\title{
Differential effect of chemical compounds on Helicobacter pylori growth and subsequent apoptosis
}

\section{Dharmendra Kashyap}

Indian Institute of Technology Indore

\section{Buddhadev Baral}

Indian Institute of Technology Indore

Tarun Prakash Verma

Indian Institute of Technology Indore

Charu Sonkar

Indian Institute of Technology Indore

Debi Chatterji

Choithram Hospital and Research Centre

Ajay Kumar Jain

Choithram Hospital and Research Centre

Hem Chandra Jha ( $\nabla$ hemcjha@iiti.ac.in )

Indian Institute of Technology Indore

Research article

Keywords: Gastric cancer, Plaque control agent, CagA, Apoptotic pathway, Growth curve

Posted Date: November 6th, 2019

DOI: https://doi.org/10.21203/rs.2.16924/v1

License: (c) (1) This work is licensed under a Creative Commons Attribution 4.0 International License. Read Full License 


\section{Abstract}

Background Helicobacter pylori (H. pylori) is well-known for its role in chronic gastritis and gastric cancer. Eradication of these carcinogenic bacteria from the gut is one of the major challenges for the clinicians. The complexity of treatment is mainly owing to, antibiotic resistance and relapse due to extra gastric reservoir in the oral cavity. Our study focuses on the isolation of $\mathrm{H}$. pylori from distinct habitats (gastric biopsy and gastric juice) of the gut microenvironment and its subsequent characterization. Further, we have also evaluated the effect of various plaque control agents on isolated strains of $\mathrm{H}$. pylori.Results The strains isolated from two different habitats of the same subject shows a striking difference in their growth pattern. Promisingly, some included chemicals are effective in growth inhibition after recommended $30 \mathrm{sec}$ treatment. The subsequent evaluation shows that chemical B (out of chemical A, B, C, D and E) is the most effective and downregulate the expression of CagA in the infected AGS cells. Conclusion For the fast time, in our study the pylori isolated from different habitat of the same subject shows differential growth pattern. Nowadays, antibiotic resistance and relapse of H. pylori make it difficult to eradicate the bacteria from gastric as well as oral reservoir. Thus, this study may help to reduce the bacteria in their oral reservoir and also control the $\mathrm{H}$. pylori migration from oral to gastric compartment.

\section{Background}

Helicobacter pylori play an important role in the development of various gastro-duodenal diseases [1]. Usually, it propagates inside the mucosal layer of the stomach, however, its significance as an obligate pathogen is still a question [2]. Possible symbiotic relationship with the host has been debated since its discovery [3]. How H. pylori cause gastric carcinogenesis pathogenesis is still unclear, in spite of several hypotheses [2]. Importantly, been good flora may producing bacteriocin-like inhibitory protein which can inhibit $H$. pylori growth [4]. However, due to any kind of loss in this good flora may increase in the number of $H$. pylori. Further, it leads to gastric acid production and ulceration [5]. Some strains of H. pylori are virulent and host factors may also responsible for disease progression [6]. Additionally, other bacteria which are acid-tolerant might also reside at the infection site within ulcers and thus enhance the problem caused by H. pylori [2].

Worldwide, H. pylori have been classified according to population genetics tool (STRUCTURE) developed by Pritchard et al [7]. Broadly, they represent geographical areas and named as: hpEurope, hpSahul, hpEastAsia, hpAsia2, hpNEAfrica, hpAfrica 1 and hpAfrica2 [8]. Also, there is a large variability in the incidence of gastric cancer worldwide [9]. Asian countries such as South Korea, China and Japan have a high incidence of gastric cancer. India is a low risk country for gastric cancer, however, it might be because of underreporting [10]. There lies a lacuna in the epidemiological studies from small towns and villages which represents a large part of the Indian population.

H. pylori seroprevalence in the adult population of developing countries varies from $55 \%$ to $92 \%$. In contrary to this, the seroprevalence of $H$. pylori in Chinese and Japanese adults is $44 \%$ and $55 \%$, 
respectively [11]. The primary manifestation of $H$. pylorin India is the duodenal ulcer, which is a major concern in India [12]. A study suggested that $56 \%$ of $H$. pylori infection in gastric cancer [13]. Therefore, a comprehensive study of $H$. pylori strains and its pathogenic properties in Indian scenario is needed.

H. pylori may be transmitted through oral-oral or oro-fecal route, and thus oral cavity may act as its possible reservoir [14]. Its presence in the oral cavity is seldom eliminated by $H$. pylori eradication therapy. Moreover, oral site may act as a source for reinfection [15]. Hence, its eradication from oral microenvironment is important $[16,17]$. Several antimicrobial (e.g. bisbiguanides, metal ions, phenols, quaternary ammonium compounds, etc.) and antiplaque agents (e.g. surfactants, essential oils) in the form of toothpaste and mouth rinses have been formulated [18]. Antiplaque agents are destroying bacterial biofilm which suppresses subsequent reinfection. In contrast, antimicrobial agents inhibit the growth or kill the target bacteria [19].

More virulent strains of $H$. pylori harbor numerous adhesins (BabA/B, SabA, AlpA/B, OipA and HopZ) and the cag (cytotoxin-associated genes) pathogenicity island encoding a type IV secretion system (T4SS) [20]. A tight bacterial contact with the host cell is established by the adhesins [21]. Further, bacterial effector proteins like CagA is delivered into host cells through this secretion system [22]. A study reported that $H$. pylori colonization may also depend on the alteration of mucosal epithelial apoptosis while doing so by chronic inflammation [23]. Surprisingly, the relation between various serotypes, their growth, alone or with gastric epithelial cells and possible occurrence in gastric cancer has not been evaluated till date. Investigation of $H$. pylori strains for their growth and subsequent host cell transformation ability may open better understanding in this domain. Hence, the present study was designed to evaluate the growth pattern of various clinically isolated strains of $H$. pylori and their response to treatment with commercially available chemical plaque control agents. The study also includes the evaluation of tumor suppressor and proto-oncogenes status in host cells as a response to treated and untreated strains of $H$. pylori.

\section{Results}

\section{Gastric biopsy and juice collection from gastritis patients for isolation of clinical strains of $H$. pylori}

Till date, there is no H. pylori strain reported from central India to the best of our knowledge. Moreover, strains from northern and southern India have been listed in previous reports [24]. Interestingly, none of the studies from India has evaluated the association between gastritis or gastric cancer progression and pathogenic $H$. pylori strains. H. pylori were successfully isolated from five out of 14 biopsy samples and four out of 11 juice samples (Table 1). After observation on selective media, gram staining was performed for all isolates (Fig. 1). Further, three clinical strains of $H$. pylori isolated from biopsies and one from juice were subjected for the amplification of $H$. pylori (CagA) through qRT-PCR (data not shown). Further validation of the clinical isolates was confirmed through nucleotide sequencing (data not shown).

\section{The growth pattern of different clinical isolates of $H$. pylori}


Growth curve of confirmed strains of $H$. pylori was determined by recording OD at $600 \mathrm{~nm}$ at various time points $(0,2,6,12,18$ and $24 \mathrm{hrs})$ and a curve was plotted (Fig. $2 \mathrm{a})$. Our results revealed that the growth of two clinical strains namely HB1 and HB5 was significantly faster compared to the other seven clinical and one reference strain (110). Interestingly, HB1 and HB5 have similar but not identical growth pattern at all examined time point (fig. 2 b). It is also fascinating that the growth pattern of HB1 and HJ1 was quite different, even though they were isolated from the same gastritis patient (fig. 2 b) Other clinical strains (HB4, HJ9, HJ10, HB10, HJ14 and HB14) shows a similar growth pattern as I10 until 24 hrs.

To have a better understanding of growth pattern, we calculated fold change in growth compared to reference strain 110 (Fig. 2 b). These graphs are plotted in the form of bar chart at all recorded time points $(0,2,6,12,18$ and $24 \mathrm{hrs})$. Three to five folds faster growth was observed in HB1 and HB5 compared to 110 at $2 \mathrm{hrs}$ and further, it is increasing up to $24 \mathrm{hrs}$. Moreover, strains such as HJ1, HB10, and HB14 were showing moderately higher growth ( 3 to 5 folds) compared to reference strain 110 from 6 hours onwards. Importantly, the growth of HB1 and HB5 were steadily increasing to $18 \mathrm{hrs}$. Hence, our study reflected two fast growing strains (HB1 and HB5) compared to other clinical isolates HB4, HJ9, HJ10, HB10, HJ14, HB14, HJ14 and reference strain I10.

\section{Confirmation of chemical plaque control agents through LCMS}

The chemical composition of the selected plaque control agents is reconfirmed through LCMS (Supp. Fig 2). Sophisticated Instrument Centre facility at IIT Indore was used for these two chemical identification techniques. Active components in the plaque control agents of $A, B, C, D$, and $E$ were determined through LCMS. Hence, LCMS characterization validates the labeled active components in plaque control agents.

\section{The growth pattern of selected clinical strains of $H$. pylori with chemical treatment}

All chosen chemicals recommend $30 \mathrm{sec}$ oral rinsing for effective plaque control. Further, our two fast growing (HB1 and HB5), two slow growing (HJ9 and HB14) and a reference strain (110) were selected for this experiment (Fig. 2 a, b). Interestingly, we observed that chemical A and C were not able to stop the growth of fast growing strain even after $30 \mathrm{sec}$ treatment (Fig. 3 a). Although, growth of fast growing strain were accelerated after 2 hrs treatment with chemical $A$ and $C$ while chemical B, D, and E were able to inhibit the growth until 24 hrs post-treatment. Additionally, slow growing strain such as HJ9 and HB14 were not able to grow until 12 hrs with all used chemicals (Fig. 3 b). However, these strains start growing from 12 hrs onwards when treated with chemical C (Fig. 3 b). Notably, our reference strain, 110, has not shown any growth after treatment with all chemicals until 24 hrs (Fig. 3 b). In all these experiments, we have used untreated strains as positive controls. Also, we had included culture media as a negative control. No substantial growth was observed for I10 when bar graph was plotted (Fig. 3 c).

In this study, we have found that chemical A was least efficient in the control of HB1 growth followed by chemical C. The substantial growth of HB1 was observed from 6 hrs onwards while treated with chemical A. Furthermore, when HB1 treated with chemical C was able to grow 12 hrs post-treatment (Fig. 3 d). Moreover, the growth of another fast growing strain, HB5, treated with chemical A and $\mathrm{C}$ was suppressed 
until only 2 hrs (Fig. 3 e). We observed considerable growth of HB5, 6 hrs onwards in A and C treatment. Importantly, chemical B, D, and E were able to suppress the growth of HB1 and HB5 until $24 \mathrm{hrs}$ in this study (Fig. 3 d, e).

\section{Selective oral rinse are restricting $H$. pylori growth even at shorter exposure}

Oral rinse $B, D$, and $E$ were found to be effective in controlling the growth of slow as well as fast growing strains at 30 sec treatment. Hence, we investigated these selected chemicals alone ( $B, D$, and $E)$ and in combination (BD, $\mathrm{BE}, \mathrm{DE}$, and $\mathrm{BDE})$ for a shorter duration of treatment $(5 \mathrm{sec})$ compared to recommended $30 \mathrm{sec}$ (Fig. 4 a, b). Even the $5 \mathrm{sec}$ treatment to fast growing strains with all effective chemicals alone and in combination were able to restrict the growth until 2 hrs (Fig. 4 a). Surprisingly, data recorded 6 hours post-treatment were demonstrating the growth of HB1 and HB5 with D, E and their combinations. Importantly, all groups in which chemical B is included shows to be restricting the growth of HB1 and HB5 (Fig. 4a). Interestingly slow growing strains HJ9, HB14, and reference strain 110 growth completely abolished with all above chemical combinations till 24 hrs (Fig. 4b). Moreover, when we treated these chemicals for $10 \mathrm{sec}$ alone and in combination, a similar pattern was found as with $30 \mathrm{sec}$ (Suppl. Fig 1). We also plotted bar graph representing fold change in growth compared to control at different time points $(0,2,6,12,18$ and $24 \mathrm{hrs})$ for clearer outlookFig. 4-c, d, e).

\section{The growth pattern of $H$. pylori after chemical treatment on BHI Agar plate:}

In addition to chemical treatment in liquid culture, we further evaluated the growth pattern on a $\mathrm{BHI}$ agar plate after $30 \mathrm{sec}$ treatment with the selected chemicals. Representative pictures of chemical treated $H$. pylori strains are shown in fig. 5 a, b, c, d, e. The images were quantified using Image $J(N I H)$ and graphs were plotted (Fig. $5 \mathrm{f}, \mathrm{g}, \mathrm{h}, \mathrm{l}, \mathrm{j}$ ). As expected, chemical treatment of $\mathrm{C}$ was not effective and $\mathrm{H}$. pylori growth was observed in the case of fast growing HB1 and HB5 after 12 hrs (Fig. 5 a, b, f, g). Moreover, we also witnessed growth after 24 hrs for slow growing strains (110, HJ9, and HB14). Surprisingly, no growth was observed in the case of chemical A treatment in all the strains, contrary to the growth in liquid culture (Fig. 5). As expected, no growth was observed after treatment with chemical B, D, and E at all the recorded time points.

\section{Gene profiling of specific gastric cancer marker and $H$. pylori after chemical treatment}

Expression of H. pylori genes namely $16 \mathrm{~s}$ rRNA, Cag A, and Bab A were investigated in this experiment. Additionally, reported gastric cancer marker such as CCND1, CDX2, PTEN[25], and MMP7 were also included [25-28]. The mixed expression profile was observed on treatment with chemicals ( $B, C, D$, and $E)$ for $5 \mathrm{sec}$ in 110 strain. On treatment with chemical B, H. pylori (16s rRNA, CagA and BabA) and GC markers (CCND1, PTEN, and MMP7) were downregulated. However, expression was higher in CDX2 with 5 sec treatment to $H$. pylori followed by $12 \mathrm{hr}$ incubation with gastric epithelial cells (AGS). H. pylori genes, 16s rRNA and Cag A are downregulated with the treatment of $C$ and $E$ (except HJ9) while Bab A was downregulated with C (Fig. 6 c, e). Moreover, PTEN and MMP7 were downregulated with chemical B, C, and $\mathrm{E}$ (Fig. $6 \mathrm{k}, \mathrm{m})$. Interestingly, $30 \mathrm{sec}$ treatment to 110 was able to abolish the expression of 16s rRNA; 
CagA; and BabA with chemical B; B, C, D and E; and B, C, and E respectively (Fig. 6 b). Our results also revealed that expression of CDX2; and MMP7 were higher with chemical $B, C$ and $D ; C, D$, and $E$ respectively with the 30 sec treatment at 12 hrs time point (Fig. 6 j, n). Similarly, when we treated another slow growing strain HJ9 for $5 \mathrm{sec}$ with chemicals followed by incubation with AGS, we observed a mixed response in gene expression profiling. In case of PTEN; and MMP7, the expression is moderately enhanced with chemical $C, D$, and $E ; B, C$, and $D$ respectively. Whereas, chemical $B$ and $E$ were able to diminish the expression of PTEN and MMP7 respectively (Fig. 6 I, n). 30 sec treatment of chemical B to the same strain followed by incubation shows slight downregulation in the expression of 16s rRNA, CagA, BabA, CCND1, CDX2, and PTEN. However, expression of MMP7 was an exception (Fig. 6). Further, when we treated HB14, another slow growing strain, for $5 \mathrm{sec}$ with chemicals followed by incubation with AGS, we observed that CagA, BabA, CCND1, CDX2, and MMP7 were considerably downregulated with chemical $B$ (Fig. 6). Additionally, CCND1, CDX2, and MMP7 were minimally expressed with the treatment of $B, C$, and E, while PTEN is downregulated with E (Fig. 6). Moreover, when we treated HB14 for 30 sec and incubated with AGS we observed downregulation of CCND1, CDX2, and PTEN with C, D, and E, while expression of MMP7 was unregulated with C, D, and E (Fig. 6 n). However, CagA was abolished with B, C, and D (Fig. 6).

Furthermore, results reflect varied gene expression profile with the treatment of 5 and 30 sec in fast growing strain HB1 (Fig. 6). Expression of CagA; and BabA were downregulated with the treatment of $B, D$, and $E$; and B, C, D, and E respectively (Fig. 6 c, d, e, f). Whereas, the expression of CCND1; CDX2; and MMP7 were enhanced with $B, C, D$ and E; E; and B respectively (Fig. 6 g, h, i, j m, n). Treatment for 30 sec to HB1 shows minimal expression of CagA with chemical B, C, and D, while; MMP7 was upregulated with all the chemicals (Fig. $6 \mathrm{~d}, \mathrm{n}$ ).

\section{Status of apoptotic gene expression}

Earlier studies have classified cells as live, apoptotic and necrotic after EB/AO staining [29]. We investigated these cells (live, apoptotic and necrotic) on infection with $30 \mathrm{sec}$ chemical treated $H$. pylori (Fig. 7). Additionally, evaluation of apoptotic pathways such as intrinsic/extrinsic/independent was performed through qRT-PCR, after treatment with these chemicals for 5 and $30 \mathrm{sec}$ (Fig. 8 ). $5 \mathrm{sec}$ exposure of chemical D in I10 strain was able to enhance the expression of APAF1, BID and BAK (Fig. 8 c, e, g). Interestingly, I10 treated with chemical C and incubated with AGS cells were able to suppress all studied apoptotic genes (Fig. 8). Whereas, other chemicals were not able to change the expression pattern of these genes considerably. Further, $30 \mathrm{sec}$ treatment of 110 and incubation with AGS cells show a different pattern (Fig. 8). I10 treated with chemical B was able to reduce the expression of all the selected genes except FADD (Fig. 8). However, treatment with chemical D and E were slightly enhancing the expression of all pro-apoptotic genes (Fig. 8).

Furthermore, when we applied these chemicals for $5 \mathrm{sec}$ on HJ9 and incubated with AGS cells, we witnessed an upsurge in APAF1 expression, while BCL2 was downregulated except in chemical D (Fig. 8 $c, m)$. Surprisingly, $30 \mathrm{sec}$ treatment of HJ9 reflected a varied gene expression compared to $5 \mathrm{sec}$. 
Chemical C, D, and E with 30 sec exposure were able to up-regulate all apoptotic genes except NOXA and PUMA (Fig. 8). However, expression of anti-apoptotic BCL2 was reduced with chemical B (Fig. $8 \mathrm{n}$ ).

Application of these chemicals for 5 sec on HB14 followed by incubation with AGS cells demonstrated that chemical D up-regulates all pro-apoptotic genes (Fig. 8). Interestingly, treatment with B was able to enhance extrinsic apoptotic regulator FADD and reduce the expression of all used intrinsic markers. It also diminished the expression of BCL2 (Fig. 8), fascinatingly, all apoptotic markers except PUMA were considerably down-regulated with the $30 \mathrm{sec}$ treatment of chemical D (Fig. 8). Moreover, the expression of FADD, APAF1, and BAK, were also reduced with chemical E (Fig. 8 b, d, f).

Furthermore, fast growing strain HB1 was treated for $5 \mathrm{sec}$ and incubated with AGS for the detection of apoptotic and anti-apoptotic genes. Here, chemical $\mathrm{C}$ and $\mathrm{E}$ were slightly up-regulating the expression of FADD, APAF1, BID and BAK (Fig. 8 a, c, e). In addition to this, chemical B treated cells were able to upregulate FADD, APAF1, BID and NOXA (Fig. $8 \mathrm{a}, \mathrm{c}, \mathrm{g}, \mathrm{k}$ ). Treatment of chemical $\mathrm{C}$ for $30 \mathrm{sec}$ to the same strain showed up-regulation of FADD, BID, and PUMA (Fig. 8 b, h, j). In contrary to this, slightly upregulation was observed for BCL2 in all chemical treatment.

\section{Discussion}

Various studies suggested the association between $H$. pylori and gastric carcinogenesis [1]. Infection of H. pylori in less developed Asian countries like India, Pakistan, Thailand, and Bangladesh is more prevalent than in more developed Asian countries like Japan and China. Interestingly, the occurrence of gastric cancer is lower in less developed Asian countries compared to Japan and China [11]. Similar enigma has been reported from African nations as compared to the Western countries [30].

Prevalence of $H$. pylori infection and the occurrence of gastric carcinogenesis does not appear to be proportionate around the world [9]. This may be attributed to the variations in the H. pylori strain pathogenicity and other associated risk factors for gastric carcinogenesis. It is important to understand the discrepancy in H. pylori pathogenicity due to geographical and host anatomical location.

In the present study, we were able to demonstrate significantly different growth patterns of isolated $H$. pylori collected from gastric biopsy and juice samples. These findings motivated us to validate the growth pattern of various clinical $H$. pylori strains through plate densitometry. The $H$. pylori isolation from two different niches of the same person may also lead to the differential growth pattern. For the first time, our study revealed that $H$. pylori isolated from the biopsy grow aggressively compared to the gastric juice of the same subject. For example, HJ1 and HB1; HJ10 and HB10; and HJ14 and HB14 were isolated from two different niches of the same subjects. There was a significant difference in the growth pattern of HJ1 and HB1, which was not remarkable in the case of HJ10 and HB10 as well as HJ14 and HB14. This finding demonstrates the importance of infection site and their micro-environment for $\mathrm{H}$. pylori dependent disease progression. Hence, these results show a specific pattern for the adaptation of $H$. pylori, which may act as a milestone in disease progression and subjected to further investigation. 
Earlier, Marshall et al showed that $H$. pylori eradication resulted in rapid gastric ulcer healing ( $92 \%$ vs. $61 \%$ ) and lower relapse rate (21\% vs. 84 ) than non-eradication [31]. Importantly, resistance to antibiotic treatment is one of the major causes for the development of primary H. pylori infection to chronic gastritis and gastric cancer [32]. Studies reported that $H$. pylori isolated from Indian population are resistant to its specific antibiotics [33]. Additionally, some strains of $H$. pylori are also resistant to the triple therapy which further increases the complication in eradication procedure [34].

Transmission mode of $H$. pylori is oral-oral or oro-fecal route [35]. Therefore oral cavity may serve as a reservoir for H. pylori (Gebara et al., 2006). Earlier studies demonstrated that relapse of H. pylori infection is mainly due to the presence of its extra gastric reservoir in the oral compartment [36]. Hence, eradication of $H$. pylori in the mouth may help in restricting its transmission and relapse from mouth to stomach [17]. In our study, the approach is to eliminate $\mathrm{H}$. pylori in oral microenvironment using mouth rinses. It will further help in treating the infection and will enhance the treatment outcome in gastric abnormalities.

Various antiplaque and antimicrobial agents are known for inhibiting the growth or killing the target bacteria present in oral microenvironment. Chemical plaque control agents may consist of chlorhexidine [37], essential oil [38], cetylpyridinium chloride [39], povidone-iodine [40], etc. In our study, we investigated the effect of these chemicals on $H$. pylori growth and its carcinogenic abilities.

Based on the growth curve analysis of various clinical isolates, we selected two fast (HB1 and HB5) and two slow growing strains (HJ9 and HB14), along with one reference strain 110, for further study. Chemical $B, D$, and $E$ were effective in fast growing strains with $30 \mathrm{sec}$ incubation. In contrary to this, oral rinse $A$ and $\mathrm{C}$ act as bacteriostatic and inhibit the growth until $2 \mathrm{hrs}$. Additionally, in the case of slow growing strains (HJ9 and HB14) all used chemicals except $C$ are effective. While chemical $C$ act as bacteriostatic up to $12 \mathrm{hrs}$. Interestingly, all used chemicals were found to be efficient to kill reference strain. 110, which has been grown for a long time in laboratory conditions. There is a need for further investigation of differential chemical response in clinical isolate vs. lab reference strain even though their growth patterns are similar.

To further validate the above experiment, plate densitometry was performed. It was observed that the growth of fast growing strains (HB1 and HB5) with the treatment of chemical C was detected at 2 hrs of liquid culture same as wild type, while 12 hrs of plate densitometry in comparison to 6 hrs of wild type. The growth of isolated strains (HJ1, HB4, HJ9, HB10, HJ10, HB14, and HJ14) was similar to the reference strain 110 whereas, strikingly HB1 and HB5 shows about 15 fold higher growth after 12 hrs. Although, these fast growing strains reflect higher growth at 2 and 6 hrs by 4 and 9 folds respectively.

Importantly, the growth of HB1 and HB5, which was observed with chemical A treatment in liquid culture, was not visible in the plate densitometry. Moreover, the growth of wild type fast growing strains could be detected within $2 \mathrm{hrs}$ in liquid culture compared to $6 \mathrm{hrs}$ in plate densitometry.

The use of oral rinse is a common practice but prolonged and repetitive use of these chemicals has an adverse effect on the user $[41,42]$. A study conducted by McGaw \& Belch shows negligible toxicity 
associated with the use of chlorhexidine mouth rinses through radiolabeling methods [43]. However, such studies were conducted in the ' 80 s, hence, further investigations with modern detection techniques are needed in long term follow-up. Investigation on povidone-iodine, reveals that it can cause acute renal failure, especially when absorbed through mucosal surfaces $[44,45]$. Even dilute solutions of povidoneiodine $(0.1$ to $20 \%)$ are toxic to human fibroblasts, granulocytes, and monocytes [46]. Toxicity of another chemical, cetyl pyridinium chloride, is noticed with vomiting, diarrhea, and abdominal pain. Ingestion of this chemical solution in concentrated form may produce burns of the mouth, pharynx, and esophagus [47]. Additionally, hemorrhagic GI tract necrosis and peritonitis have also been reported [47]. Prolonged exposure of common constituents of oral rinses like essential oils, menthol, thymol, etc. can act as potential allergens in various ethnical races [48]. Moreover, some manufacturers produce alcohol-based mouthwashes which can cause complications like irritation of oral mucosa and may be hazardous if ingested accidentally during pregnancy [49].

Our focus in this study was to reduce the time of exposure to minimize the possibility of toxicity caused by these chemicals. To achieve our goal, we performed the $5 \mathrm{sec}$ treatment and compared it with $30 \mathrm{sec}$ treatment of H. pylori.

We selected those chemicals which were effective in the $30 \mathrm{sec}$ treatment in combinations and alone. As expected, growth of slow growing strains (110, HJ9, and HB14) was controlled through all used chemicals at $5 \mathrm{sec}$ incubation. However, only chemical B and its combination seem to be potent for all H. pylori strains. Strikingly, chemicals D and E, which were effective on $30 \mathrm{sec}$ treatment, were unable to show comparable results with fast growing strains. The high efficacy of chemical B may be attributed to its large dicationic molecule (Chlorhexidine) which can adsorb onto negatively charged bacterial cell walls [50]. This increases the permeability of the inner membrane and leads to the leakage of low molecular weight components. At concentration $0.2 \%$, this damage is permanent and hence act as a bactericidal agent [50].

Further, in our study we evaluated the genes like CCND1, CDX2, PTEN, and MMP7 which are related to $H$. pylori mediated gastric cancer progression.

The cag pathogenicity island (cag-PAl) is one of the major virulence determinants of $H$. pylori. Irrespective of the growth pattern variation in isolated $H$. pylori strains, there is significant downregulation of CagA gene with chemical B. Also long exposure of $C$ and $D$ to $I 10, H B 14$, and HB1 diminish the expression of CagA. Here Cag A expression imitates the growth of $H$. pylori after chemical B treatment.

$\mathrm{EB} / \mathrm{AO}$ staining has been used as a gold standard to differentiate between live, apoptotic (early/late) and necrotic cells. We observed that $H$. pylori treated with chemical B and incubated with AGS shows more cells in the late apoptotic stage. While with chemical C, D and E treatment, cells are either in early apoptotic stage or live. This reflects that chemical B is most effective among all the studied chemicals.

To understand the growth arrest of H. pylori through used chemicals, we have mapped several mechanisms of cell death mainly apoptosis and necrosis. In brief, we have observed genes regulated for 
apoptosis by the intrinsic, extrinsic or independent pathways. Interestingly, extrinsic apoptotic marker FADD is slightly enhanced in slow growing strain HJ9 and HB14 with selective chemicals. Although, studies suggest that FADD is expressed on the surface of cytotoxic T lymphocytes (CTLs) and natural killer (NK) cells as part of their armamentarium against infected or transformed cells.

Moreover, markers for the intrinsic pathway, APAF1 shows higher expression during shorter exposure of chemical B, C, D, and E to HJ9, while the result is not similar for longer exposure. Notably, BID shows selective up-regulation with chemical $D$ in slow growing strains. Studies have demonstrated that both APAF1 and BID belongs to the BCL2 family and act with the mitochondria-related apoptotic pathway [51, 52]. However, expression pattern for BAK, PUMA, and NOXA was not decisive with used chemicals for all included $H$. pylori strains. PUMA and NOXA belong to pro-apoptotic $\mathrm{BH} 3$ only family which regulates BCL2 activity [53]. Interestingly, anti-apoptotic gene, BCL2, was noticeably down-regulated in 5 sec treatment while not in $30 \mathrm{sec}$ with the applied chemicals.

\section{Conclusion}

H. pylori adaptation to varying physiological habitat in the host may be responsible for the differences in its growth and pathogenicity. For avoiding the challenges of relapse and antibiotic resistance we used chemical formulations and found that these are effective against CagA. Some of the changeability in outcome can be attributed to different bacterial strain specificity, host susceptibility, and the type of response elicited in the infected host. There is a need for detailed study about the molecular pathways modulated by the chemical in bacteria. These studies will also open wide scope to apply various bactericidal chemical combinations for the treatment and eradication of $H$. pylori infection.

\section{Materials And Methods}

\section{Patient recruitment:}

The endoscopic procedure was performed after getting informed written consent from the patients. The protocol for the present study was approved by the ethical committee of the Indian Institute of Technology Indore, as well as Choithram Hospital Indore (approval number FD090) and all procedures were performed by following the revised declaration of Helsinki 2000. We collected only Rapid Urease Test (RUT) positive 14 biopsies (male $=9$ and female=5) and 11 gastric juice (male=6, female=5) samples from gastritis patients (Table 1). Patients undergoing antibiotic treatment against $H$. pylori were excluded for sampling. Moreover, for the further processing, biopsy samples were immediately placed in a microcentrifuge tube containing Brucella broth (BD Difco Cat No. 8806541) with 20\% glucose (Hi-media, Cat No. TC130), while gastric juice was collected in sterile $15 \mathrm{ml}$ centrifuge tube. Samples were transported to IIT Indore in ice.

Table 1: Gastric biopsy and juice collection from gastritis patients 


\begin{tabular}{|c|c|c|c|c|c|c|}
\hline Sr. No. & \multicolumn{2}{|c|}{ Sample } & Sex & RUT status & \multicolumn{2}{|c|}{ Grown sample } \\
\cline { 2 - 6 } & HB & HJ & & & \multicolumn{2}{l}{} \\
\hline 1 & $\ddot{\mathrm{u}}$ & $\ddot{\mathrm{u}}$ & $\mathrm{F}$ & + & HB1 & HJ1 \\
\hline 2 & $\ddot{\mathrm{u}}$ & $\ddot{\mathrm{u}}$ & $\mathrm{M}$ & + & - & - \\
\hline 3 & $\ddot{\mathrm{u}}$ & $\ddot{\mathrm{u}}$ & $\mathrm{M}$ & + & - & - \\
\hline 4 & $\ddot{\mathrm{u}}$ & $\hat{\mathrm{u}}$ & $\mathrm{M}$ & + & HB4 & - \\
\hline 5 & $\ddot{\mathrm{u}}$ & $\hat{\mathrm{u}}$ & $\mathrm{M}$ & + & HB5 & - \\
\hline 6 & $\ddot{\mathrm{u}}$ & $\hat{\mathrm{u}}$ & $\mathrm{M}$ & + & - & - \\
\hline 7 & $\ddot{\mathrm{u}}$ & $\ddot{\mathrm{u}}$ & $\mathrm{M}$ & + & - & - \\
\hline 8 & $\ddot{\mathrm{u}}$ & $\ddot{\mathrm{u}}$ & $\mathrm{F}$ & + & - & - \\
\hline 9 & $\ddot{\mathrm{u}}$ & $\ddot{\mathrm{u}}$ & $\mathrm{F}$ & + & - & HJ9 \\
\hline 10 & $\ddot{\mathrm{u}}$ & $\ddot{\mathrm{u}}$ & $\mathrm{M}$ & + & HB10 & HJ10 \\
\hline 11 & $\ddot{\mathrm{u}}$ & $\ddot{\mathrm{u}}$ & $\mathrm{M}$ & + & - & - \\
\hline 12 & $\ddot{\mathrm{u}}$ & $\ddot{\mathrm{u}}$ & $\mathrm{M}$ & + & - & - \\
\hline 13 & $\ddot{\mathrm{u}}$ & $\ddot{\mathrm{u}}$ & $\mathrm{F}$ & + & - & - \\
\hline 14 & $\ddot{\mathrm{u}}$ & $\ddot{\mathrm{u}}$ & $\mathrm{F}$ & + & HB14 & HJ14 \\
\hline
\end{tabular}

RUT- Rapid Urease Test, HB- Gastric Biopsy, HJ- Gastric Juice, M- Male, F- Female

\section{Culturing of $H$. pylori from clinical samples}

The biopsy samples were homogenized by using a glass rod. One loopful of the homogenous sample was streaked on Columbia agar plate (Himedia ME144) containing the $H$. pylori selective antibiotics, (5mg/L cefsulodin, $10 \mathrm{mg} / \mathrm{L}$ vancomycin, $5 \mathrm{mg} / \mathrm{L}$ amphotericin $\mathrm{B}, 5 \mathrm{mg} / \mathrm{L}$ trimethoprim and $10 \%$ defibrinated blood, BD, Cat. No. 254005). The plates were incubated in a microaerophilic chamber (Whitley DG 250) containing specific growth condition (i.e. $85 \% \mathrm{~N}_{2}, 10 \% \mathrm{CO}_{2}$ and $5 \% \mathrm{O}_{2}$ ) at $37^{\circ} \mathrm{C}$. The same procedure was followed for gastric juice samples and the colonial growth was observed for the next 3-4 days. H. pylori isolated form biopsy and gastric juice samples were named as HB and HJ respectively, followed by a number representing the sequence of sampling. In the present study, we also used I10 as a reference $H$. pylori strain which was kindly gifted by Dr. Ashish Kumar Mukhopadhyay from the National Institute of Cholera and Enteric Diseases (NICED) Kolkata.

\section{Culturing of clinical isolates in liquid and solid growth medium}

From each sample, a single colony was picked from the Columbia agar plate and inoculated in brain heart infusion media (BHI, Cat. No. 237500- BD Brain Heart Infusion broth), containing 10\% Fetal Bovine Serum (FBS Hi-media, Cat. No. RM-10432) with 3X H. pylori selective antibiotics in a snap cap tube (BD, 
Cat. No. 352001). Simultaneously, it was also streaked on a BHI agar plate containing the same concentration of FBS and antibiotics. Both broth and plate were incubated in a similar growth condition as described above.

\section{Gram staining:}

To identify isolated strains, gram staining was performed. Preparation of smear was done after suspending fresh culture in $100 \mu \mathrm{l}$ PBS followed by air-drying and heat-fixation over the flame. The smear was flooded with crystal violet for 60 seconds and the excess stain was washed off with distilled water. The smear was again flooded with gram iodine for 60 seconds. It was then rinsed with distilled water and blot dried followed by counterstaining with safranin for 30 seconds. The slides were again washed and observed under the microscope (100X - oil immersion lens) (Nikon Eclipse E100 upright microscope) (Fig. 1).

\section{Growth curve:}

The isolated $\mathrm{H}$. pylori strains were analyzed for the growth pattern until $24 \mathrm{hrs}$. In brief, the isolates were cultured in a $14 \mathrm{ml}$ round bottom snap cap tube (BD) in biological duplicates by setting initial $\mathrm{OD}_{600} 0.05$ which correspond to approximately 80 million CFU per ml [54]. Further, they were incubated in the microaerophilic chamber as mentioned above. 150 $\mathrm{\mu l}$ grown culture was placed in duplicate in 96 well flat bottom plate and OD were recorded at 600nm (Synergy H1 Hybrid Multi-Mode Reader, BioTek). Final OD value was normalized with media as a negative control.

\section{DNA isolation:}

H. pylori culture was harvested in phosphate-buffered saline for DNA extraction at $\mathrm{OD}_{600 \mathrm{~nm}}$ of 0.2-0.6. The pelleted cells were suspended in extraction solution (10mM Tris pH 8.0, $15 \mathrm{mM} \mathrm{NaCl}, 10 \mathrm{mM}$ EDTA, $0.5 \%$ SDS) and kept at $55^{\circ} \mathrm{C}$ for $1 \mathrm{hrs}$. Proteinase $\mathrm{K}$ (Thermo fisher scientific) solution $(20 \mathrm{mg} / \mathrm{mL}$ ) was added $(1 \mathrm{mg} / \mathrm{ml})$ and samples were incubated overnight at $37^{\circ} \mathrm{C}$. RNAse-A (Himedia) was added $(0.1 \mathrm{mg} /$ $\mathrm{ml}$ ) to the solution and kept at $37^{\circ} \mathrm{C}$ for $1 \mathrm{hr}$. The DNA was extracted with the phenol-chloroform-isoamylalcohol method [55].

\section{PCR detection:}

H. pylori DNA samples were amplified by Platinum ${ }^{\mathrm{TM}}$ Taq DNA Polymerase (Invitrogen $^{\mathrm{TM}}$, Cat. No.10966026). The reaction volume for PCR was $50 \mu \mathrm{L}(50 \mathrm{mM} \mathrm{KCl}, 1.5 \mathrm{mM} \mathrm{MgCl}, 200 \mathrm{mM}$ dNTPs, 10 $\mathrm{mM}$ Tris- $\mathrm{HCl}$ ( $\mathrm{pH}=8.3), 10 \mathrm{pmol}$ primer, 2.5 units Taq polymerase and $100 \mathrm{ng}$ of DNA template). CagA specific forward primer 5'GCCATCATGTTTTAGGCTACC3' and reverse primer 5'GACGCCCTAGGGAATGATC3' respectively were used for amplification (product size -183 bp). The amplification was carried out with initial denaturation at $94^{\circ} \mathrm{C}$ for 7 minutes followed by 40 cycles of denaturation, annealing, extension and final extension at $94^{\circ} \mathrm{C}$ for 2 minute, $55^{\circ} \mathrm{C}$ for $30 \mathrm{sec}, 72^{\circ} \mathrm{C}$ for 30 sec and $72^{\circ} \mathrm{C}$ for 10 minutes respectively. Analysis of the amplified products were done by gel 
electrophoresis using $2.5 \%$ agarose gel and stained with $0.5 \mu \mathrm{g} / \mathrm{ml}$ ethidium bromide. Product size was confirmed by using 50-bp DNA ladder (Hi-Media, cat no.MBT130). The image of gel was acquired on a gel documentation system (ImageQuant LAS 4000, GE Healthcare Life Sciences).

\section{Chemical plaque control agents:}

Five different commercially available mouthwash solutions were purchased from local pharmacy store and were assigned name A, B, C, D \& E. Mouthwash A contains cetylpyridinium chloride $0.075 \% \mathrm{w} / \mathrm{W}$, mouthwash $B$ contains chlorhexidine $(0.2 \% \mathrm{w} / \mathrm{v})$, mouthwash $\mathrm{C}$ contains naturally derived clove oil $(0.1 \mathrm{mg} / \mathrm{gm})$ (cloves extracts), mouthwash D contains thymol (thyme) $0.064 \%$, methyl salicylate (wintergreen) $0.06 \%$ and eucalyptol (eucalyptus) $0.092 \%$, and mouthwash E contains $2 \% \mathrm{w} / \mathrm{v}$ povidoneiodine.

\section{LC-MS:}

Mass and spectral analysis were done by Bruker Daltonik, Benchtop, High-Performance Electrospray Ionization Quadrupole time-of-flight LC-MS spectrometer designed for estimation of an exact mass of the components present in mouthwash solutions. The bactericidal function of cetyl-pyridinium chloride (CPC) or 1-hexadecylpyridinium chloride, or chlorhexidine gluconate (CHG), clove oil, menthol/thymol and povidone/iodine is well known and used in various antibacterial products like mouthwashes, throat sprays, nasal sprays. We have got exact mass spectra at 304.5, 253, 205.1, 212.1 and 102.12 for CPC, chlorhexidine, clove oil, thymol and povidone/iodine respectively.

\section{H. pylori growth inhibition by mouthwash:}

Povidone-iodine (2\%) was diluted in water (1:1), while other mouthwashes were used in provided concentrations. A fixed number of $H$. pylori $\left(6 \times 10^{7}\right)$ were incubated with $1 \mathrm{ml}$ of all mouthwashes for 30 $\mathrm{sec}, 10 \mathrm{sec}$ and $5 \mathrm{sec}$, followed by centrifugation at $3000 \mathrm{rpm}$ for $5 \mathrm{~min}$. The control group was left untreated. Pellets were suspended in $0.5 \mathrm{ml}$ of BHI media containing $10 \%$ FBS and selective antibiotics followed by incubation in microaerophilic conditions as mentioned above. Optical density was taken at $600 \mathrm{~nm}$ in 96 well plates. $150 \mu \mathrm{l}$ of culture was taken in each well in duplicates (Synergy H1 microplate reader, Biotek). The growth curve was plotted at $0,6,12,18$, and 24 hrs time points.

\section{Densitometry of $H$. pylori growth on $\mathrm{BH}$ agar plate}

Plate densitometry study on a $\mathrm{BHI}$ agar plate was performed to validate the experiments in the liquid medium. To check the growth of $H$. pylori (HB1, HB5, HJ9, HB14, and I10) on BHI agar plate, $1 \times 10^{7}$ bacteria were taken $\left(\mathrm{OD}_{600} 0.3\right.$ represents 500 million CFU per $\mathrm{ml}$ ) [54] and suspended in $100 \mu \mathrm{L}$ of $\mathrm{BHI}$ broth and then spread by using glass spreader. Further, images of plates were obtained at 0, 6, 12 and 24 hrs and data were analyzed by measuring the mean grey value using Image $\mathrm{J}(\mathrm{NIH})$. In addition to this, the growth of bacteria on a $\mathrm{BHI}$ agar plate after $30 \mathrm{sec}$ chemical treatment was also determined. $0.5 \times 10^{7}$ bacteria were taken and subjected to centrifugation at $3000 \mathrm{rpm}$ for $5 \mathrm{~min}$. The supernatant was 
discarded and the pellet was treated with $333 \mu \mathrm{L}$ of the selected chemicals (A, B, C, D, and E) for $30 \mathrm{sec}$, the treatment was stopped by centrifugation at $3000 \mathrm{rpm}$ for $5 \mathrm{~min}$ and the supernatant was discarded. The pellets were suspended in $50 \mu \mathrm{L}$ of $\mathrm{BHI}$ broth and spread in half of the plate and incubated in a microaerophilic condition followed by taking an image at various time intervals. We have shown $\mathrm{BHI}$ plates containing $H$. pylori growth and further, for better understanding we calculated the fold change in growth. The obtained data was plotted into graph fig.2 (c, d) and fig.5.

\section{RNA isolation and gene expression study through qRT-PCR}

Fixed number $\left(6 \times 10^{7} \mathrm{CFU}\right.$ per $\left.\mathrm{mL}\right)$ of $H$. pylori isolates $(110, \mathrm{HJ} 9, \mathrm{HB} 14, \mathrm{HB} 1)$ were treated with $1 \mathrm{ml}$ of oral rinse for $30 \mathrm{sec}$ and $5 \mathrm{sec}$. Here, oral rinse A was excluded from cell culture study because of alcoholic constituents. Further, H. pylori isolates were incubated with AGS (Adenocarcinoma Gastric) cells under specific conditions $\left(5 \% \mathrm{CO}_{2}, 37^{\circ} \mathrm{C}\right)$ for $12 \mathrm{hrs}$. At $12 \mathrm{hrs}$ time point, the pellet was collected by centrifugation (1600 rpm for $5 \mathrm{~min}$ ) and washed twice with PBS. Total RNA was isolated by using Ribozol reagent (VWR ${ }^{T M}$ Cat No. N580) as per the manufacturer's instruction. cDNA was synthesized using superscript II reverse transcriptase kit (Takara, Cat No. RR820Q) according to the manufacturer's instruction. Quantitative real-time PCR analysis was performed using the AriaMx Real-Time PCR System (Agilent technologies 5301 Stevens Creek Blvd Santa Clara, CA 95051 USA), for assessment of gastric cancer marker genes (CCND1, CDX2, PTEN, and MMP7), apoptotic genes (FADD, APAF1, BID, BAK, NOXA, PUMA and BCL2) and pathogen-associated genes (CagA, BabA and 16s-rRNA), (sup. table).

\section{Ethidium bromide and acridine orange (EB/AO) assay}

$\mathrm{EB} / \mathrm{AO}$ dual staining was performed for the assessment of the apoptotic, necrotic and live-cells after infection with chemically treated $H$. pylori. The experiment was performed in duplicates and the image was acquired by confocal microscopy (Olympus IX83) at 10X with $3 \mathrm{X}$ zoom in triplicates. The working concentration of acridine orange and ethidium bromide was $100 \mu \mathrm{g} / \mathrm{ml}$ each [56].

\section{Abbreviations}

HB- Human Gastric Biopsy, HJ- Human Gastric Juice.

\section{Declarations}

\section{Ethics approval and consent to participate}

The protocol for the present study was approved by the ethical committee of the Indian Institute of Technology Indore, as well as Choithram Hospital Indore (approval number FD090) and all procedures were performed by following the revised declaration of Helsinki 2000.

\section{Consent for publication}


Not applicable

\section{Availability of data and materials}

All-important data are presented in manuscript or in supplementary figures. Some other supporting information those may not be crucial or affecting result interpretation is not included. Moreover, these data can be available from the corresponding author on reasonable request.

\section{Competing interests}

The authors declare that they have no competing interests

\section{Funding}

This project was supported by Council of Scientific and Industrial Research grant no 37(1693)/17/EMR-II and Department of Science and Technology as Ramanujan fellowship grant no. SB/S2/RJN-132/20/5. DST-EMR: EMR/2017/001637.

\section{Authors' contributions}

HCJ coordinated the project and designed experiments. CS, DC and AKJ collected samples from patients. DK, BB, TPV carried out experiments. BB and TPV analyzed data. DK, BB, and TPV wrote the manuscript. All authors revised and approved the manuscript.

\section{Acknowledgements}

We appreciate Dr. Ashish Kumar Mukhopadhyay (National Institute of Cholera and Enteric Diseases, Kolkata) for providing the Helicobacter pylori strain I10. We also appreciate Sophisticated Instrumentation Centre, IIT Indore for Confocal microscopy and LC-MS facility.

\section{References}

1. Yamaoka Y. Mechanisms of disease: Helicobacter pylori virulence factors. Nat Rev Gastroenterol Hepatol. 2010;7:629-41.

2. Mishra S. Is Helicobacter pylori good or bad? Eur J Clin Microbiol Infect Dis. 2013;32:301-4.

3. Carroll IM, Khan AA, Ahmed N. Revisiting the pestilence of Helicobacter pylori: insights into geographical genomics and pathogen evolution. Infect Genet Evol J Mol Epidemiol Evol Genet Infect Dis. 2004;4:81-90.

4. Ishihara K, Miura T, Kimizuka R, Ebihara Y, Mizuno Y, Okuda K. Oral bacteria inhibit Helicobacter pylori growth. FEMS Microbiol Lett. 1997;152:355-361.

5. Kusters JG, van Vliet AHM, Kuipers EJ. Pathogenesis of Helicobacter pylori Infection. Clin Microbiol Rev. 2006;19:449-90. 
6. Bravo D, Hoare A, Soto C, Valenzuela MA, Quest AF. Helicobacter pylori in human health and disease: Mechanisms for local gastric and systemic effects. World J Gastroenterol. 2018;24:3071-89.

7. Porras-Hurtado L, Ruiz Y, Santos C, Phillips C, Carracedo Á, Lareu M. An overview of STRUCTURE: applications, parameter settings, and supporting software. Front Genet. 2013;4:98.

8. Moodley Y, Linz B, Bond RP, Nieuwoudt M, Soodyall H, Schlebusch CM, et al. Age of the association between Helicobacter pylori and man. PLoS Pathog. 2012;8:e1002693.

9. Brenner $H$, Rothenbacher D, Arndt V. Epidemiology of stomach cancer. In: Cancer Epidemiology. Springer; 2009. p. 467-477.

10. Servarayan Murugesan C, Manickavasagam K, Chandramohan A, Jebaraj A, Jameel ARA, Jain MS, et al. Gastric cancer in India: epidemiology and standard of treatment. Updat Surg. 2018;70:233-9.

11. Singh K, Ghoshal UC. Causal role of Helicobacter pylori infection in gastric cancer: an Asian enigma. World J Gastroenterol WJG. 2006;12:1346.

12. Graham DY, Lu H, Yamaoka Y. African, Asian or Indian enigma, the East Asian Helicobacter pylori: facts or medical myths. J Dig Dis. 2009;10:77-84.

13. Ghoshal UC, Tiwari S, Pandey R, Dhingra S, Ghoshal U, Singh H, et al. Frequency of Helicobacter pylori and CagA Antibody in Patients with Gastric Neoplasms and Controls: The Indian Enigma: 122. Am J Gastroenterol. 2005;100:S64.

14. Gebara ECE, Faria CM, Pannuti C, Chehter L, Mayer MPA, Lima L. Persistence of Helicobacter pylori in the oral cavity after systemic eradication therapy. J Clin Periodontol. 2006;33:329-333.

15. Anand PS, Kamath KP, Anil S. Role of dental plaque, saliva and periodontal disease in Helicobacter pylori infection. World J Gastroenterol WJG. 2014;20:5639-53.

16. Zarić S, Bojić B, Janković Lj, Dapčević B, Popović B, Čakić S, et al. Periodontal Therapy Improves Gastric Helicobacter pylori Eradication. J Dent Res. 2009;88:946-50.

17. Anand PS, Nandakumar K, Shenoy KT. Are dental plaque, poor oral hygiene, and periodontal disease associated with Helicobacter pylori infection? J Periodontol. 2006;77:692-698.

18. Marsh PD. Controlling the oral biofilm with antimicrobials. J Dent. 2010;38:S11-5.

19. Baehni PC, Takeuchi Y. Anti-plaque agents in the prevention of biofilm-associated oral diseases. Oral Dis. 2003;9:23-9.

20. Backert S, Clyne M, Tegtmeyer N. Molecular mechanisms of gastric epithelial cell adhesion and injection of CagA by Helicobacter pylori. Cell Commun Signal. 2011;9:28.

21. Amieva MR, El-Omar EM. Host-Bacterial Interactions in Helicobacter pylori Infection. Gastroenterology. 2008;134:306-23.

22. Backert S, Tegtmeyer N, Fischer W. Composition, structure and function of the Helicobacter pylori cag pathogenicity island encoded type IV secretion system. Future Microbiol. 2015;10:955-965.

23. Shirin H, Moss SF. Helicobacter pylori induced apoptosis. Gut. 1998;43:592-4.

24. Kauser F, Hussain MA, Ahmed I, Ahmad N, Habeeb A, Khan AA, et al. Comparing genomes of Helicobacter pylori strains from the high-altitude desert of Ladakh, India. J Clin Microbiol. 
2005;43:1538-1545.

25. Guo J, Li S, Guo G. Long noncoding RNA AFAP1-AS1 promotes cell proliferation and apoptosis of gastric cancer cells via PTEN/p-AKT pathway. Dig Dis Sci. 2017;62:2004-2010.

26. Canales J, Valenzuela M, Bravo J, Cerda-Opazo P, Jorquera C, Toledo H, et al. Helicobacter pylori induced phosphatidylinositol-3-OH kinase/mTOR activation increases hypoxia inducible factor-1a to promote loss of cyclin D1 and G0/G1 cell cycle arrest in human gastric cells. Front Cell Infect Microbiol. 2017;7:92.

27. Bai Z-G, Ye Y-J, Shen D-H, Lu Y-Y, Zhang Z-T, Wang S. PTEN expression and suppression of proliferation are associated with $\mathrm{Cdx} 2$ overexpression in gastric cancer cells. Int $\mathrm{J}$ Oncol. 2013;42:1682-1691.

28. Ogden SR, Noto JM, Allen SS, Patel DA, Romero-Gallo J, Washington MK, et al. Matrix Metalloproteinase-7 and Premalignant Host Responses in Helicobacter pylori-Infected Mice. Cancer Res. 2010;70:30-35.

29. Ribble D, Goldstein NB, Norris DA, Shellman YG. A simple technique for quantifying apoptosis in $96-$ well plates. BMC Biotechnol. 2005;5:12.

30. Hooi JKY, Lai WY, Ng WK, Suen MMY, Underwood FE, Tanyingoh D, et al. Global Prevalence of Helicobacter pylori Infection: Systematic Review and Meta-Analysis. Gastroenterology. 2017;153:420-9.

31. Ramakrishna BS. Helicobacter pylori infection in India: the case against eradication. Indian J Gastroenterol. 2006;25:25.

32. Ansari S, Yamaoka Y. Current understanding and management of Helicobacter pylori infection: an updated appraisal. F1000Research. 2018;7.

33. Datta S, Chattopadhyay S, Patra R, De R, Ramamurthy T, Hembram J, et al. Most Helicobacter pylori strains of Kolkata in India are resistant to metronidazole but susceptible to other drugs commonly used for eradication and ulcer therapy. Aliment Pharmacol Ther. 2005;22:51-7.

34. Thyagarajan S, Ray P, Das BK, Ayyagari A, Khan AA, Dharmalingam S, et al. Geographical difference in antimicrobial resistance pattern of Helicobacter pylori clinical isolates from Indian patients: Multicentric study. J Gastroenterol Hepatol. 2003;18:1373-8.

35. Salles N, Mégraud F. Current management of Helicobacter pylori infections in the elderly. Expert Rev Anti Infect Ther. 2007;5:845-856.

36. Castro-Muñoz LJ, González-Díaz CA, Muñoz-Escobar A, Tovar-Ayona BJ, Aguilar-Anguiano LM, Vargas-Olmos R, et al. Prevalence of Helicobacter pylori from the oral cavity of Mexican asymptomatic children under 5 years of age through PCR. Arch Oral Biol. 2017;73:55-9.

37. Mathur S, Mathur T, Srivastava R, Khatri R. Chlorhexidine: The gold standard in chemical plaque control. Natl J Physiol Pharm Pharmacol. 2011;1:45.

38. Marchetti E, Mummolo S, Di Mattia J, Casalena F, Di Martino S, Mattei A, et al. Efficacy of essential oil mouthwash with and without alcohol: a 3-Day plaque accumulation model. Trials. 2011;12:262. 
39. Hu D, Li X, Sreenivasan PK, DeVizio W. A randomized, double-blind clinical study to assess the antimicrobial effects of a cetylpyridinium chloride mouth rinse on dental plaque bacteria. Clin Ther. 2009;31:2540-8.

40. Roopashri G, Jayanthi K, Guruprasad R. Efficacy of benzydamine hydrochloride, chlorhexidine, and povidone iodine in the treatment of oral mucositis among patients undergoing radiotherapy in head and neck malignancies: A drug trail. Contemp Clin Dent. 2011;2:8-12.

41. Rath SK, Singh M. Comparative clinical and microbiological efficacy of mouthwashes containing 0.2\% and $0.12 \%$ chlorhexidine. Dent Res J. 2013;10:364.

42. Patel R, Gallagher J, Chapple I. Question from practice: how to select the right mouthwash. Acute Pain. 2019;14:44.

43. McGaw WT, Belch A. Oral complications of acute leukemia: prophylactic impact of a chlorhexidine mouth rinse regimen. Oral Surg Oral Med Oral Pathol. 1985;60:275-280.

44. Beji S, Kaaroud H, Ben FM, Abderrahim E, Zghidi S, Ben FH, et al. Acute renal failure following mucosal administration of povidone iodine. Presse Medicale Paris Fr 1983. 2006;35 1 Pt 1:61-63.

45. Gautam SS, Gautam RS. A case of ARF after chromopertubation with povidone iodine. Int J Reprod Contracept Obstet Gynecol. 2018;7:2982-4.

46. Balin AK, Pratt L. Dilute povidone-iodine solutions inhibit human skin fibroblast growth. Dermatol Surg Off Publ Am Soc Dermatol Surg Al. 2002;28:210-4.

47. Pohanish RP. Sittig's Handbook of Toxic and Hazardous Chemicals and Carcinogens. William Andrew; 2011.

48. Antignac E, Nohynek GJ, Re T, Clouzeau J, Toutain H. Safety of botanical ingredients in personal care products/cosmetics. Food Chem Toxicol. 2011;49:324-41.

49. Reisfield GM, Goldberger BA, Pesce AJ, Crews BO, Wilson GR, Teitelbaum SA, et al. Ethyl glucuronide, ethyl sulfate, and ethanol in urine after intensive exposure to high ethanol content mouthwash. $J$ Anal Toxicol. 2011;35:264-268.

50. Jones CG. Chlorhexidine: is it still the gold standard? Periodontol 2000. 1997;15:55-62.

51. Patwardhan GA, Beverly LJ, Siskind LJ. Sphingolipids and mitochondrial apoptosis. J Bioenerg Biomembr. 2016;48:153-168.

52. Gryko M, Pryczynicz A, Zareba K, Kędra B, Kemona A, Guzińska-Ustymowicz K. The expression of Bcl2 and BID in gastric cancer cells. J Immunol Res. 2014;2014.

53. Youle RJ, Strasser A. The BCL-2 protein family: opposing activities that mediate cell death. Nat Rev Mol Cell Biol. 2008;9:47-59.

54. Blanchard TG, Nedrud JG. Laboratory maintenance of Helicobacter species. Curr Protoc Microbiol. 2012;24:8B-1.

55. Chachaty E, Saulnier P. Bacterial DNA Extraction for Polymerase Chain Reaction and Pulsed-Field Gel Electrophoresis. In: Nucleic Acid Protocols Handbook, The. New Jersey: Humana Press; 2000. p. 336. doi:10.1385/1-59259-038-1:33. 
56. Jha HC, Lu J, Saha A, Cai Q, Banerjee S, Prasad MAJ, et al. EBNA3C-Mediated Regulation of Aurora Kinase B Contributes to Epstein-Barr Virus-Induced B-Cell Proliferation through Modulation of the Activities of the Retinoblastoma Protein and Apoptotic Caspases. J Virol. 2013;87:12121-38.

\section{Figures}




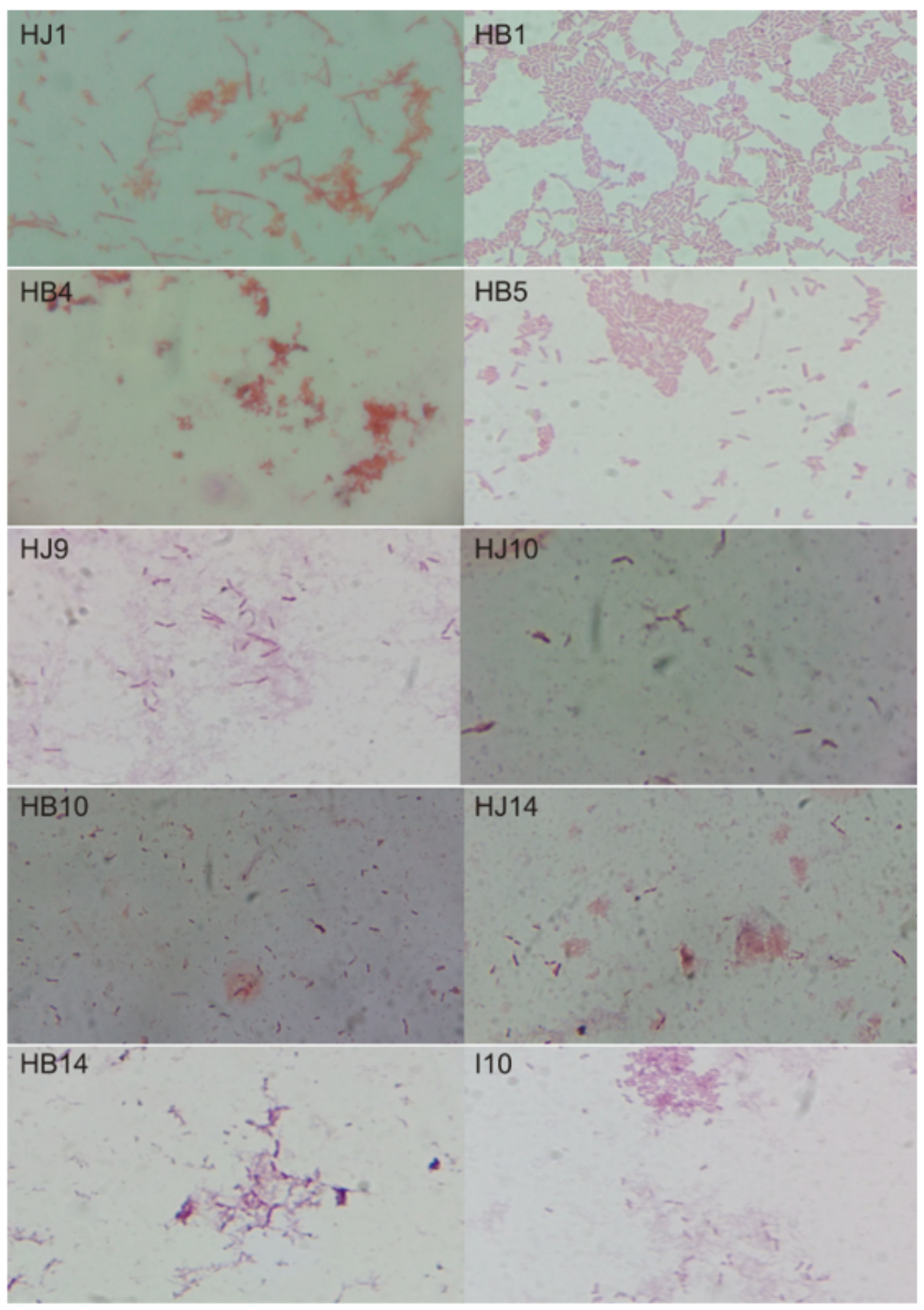

\section{Figure 1}

Identification of bacteria through gram staining. Gram staining of different clinical isolates of $\mathrm{H}$. Pylori namely; 110, HJ9, HB10, HJ10, HB14, HJ14, HB1, HJ1, HB4 and HB5 showing typical gram-negative bacteria. 
(a)

Growth Curve
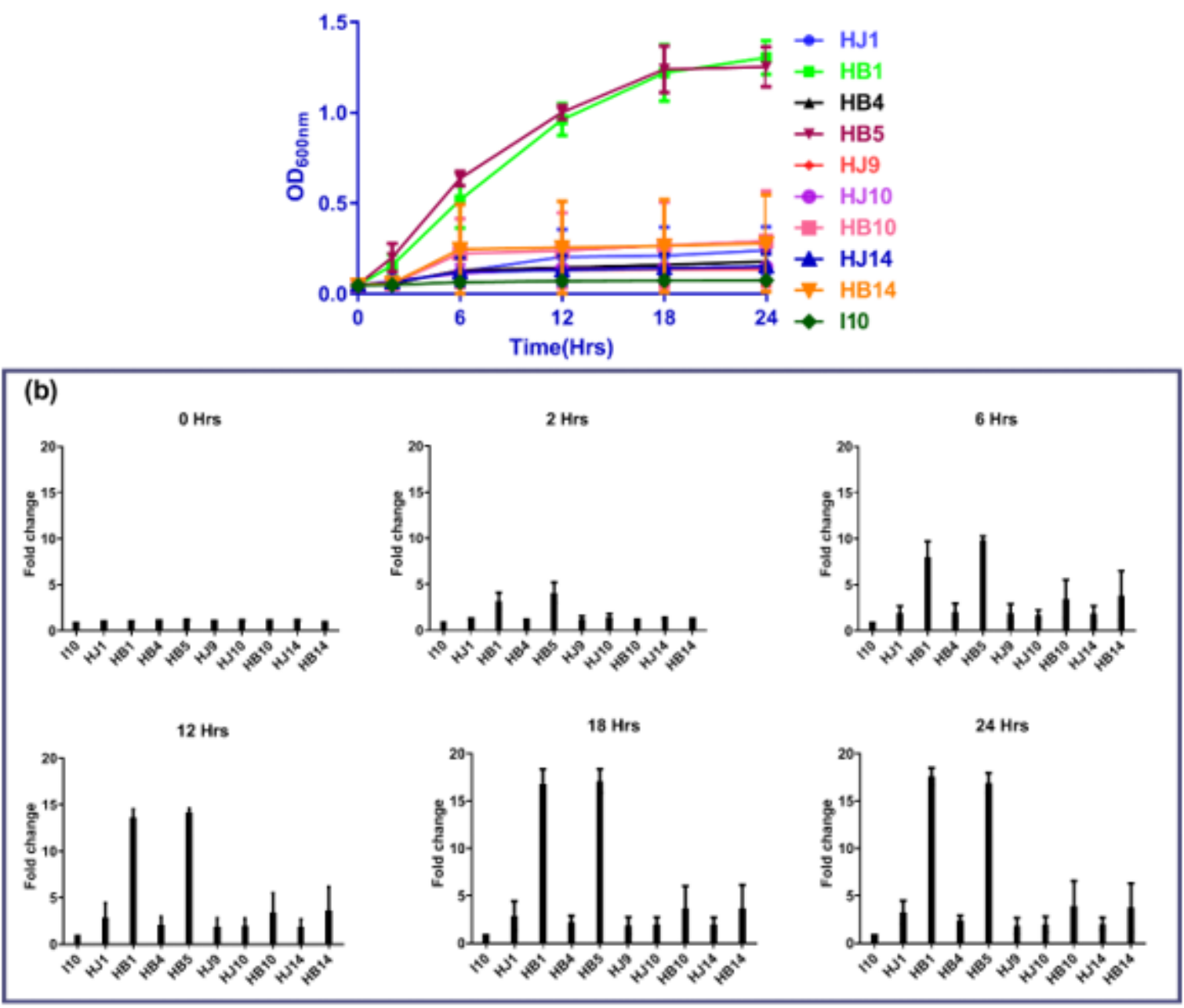

(c)

(d)
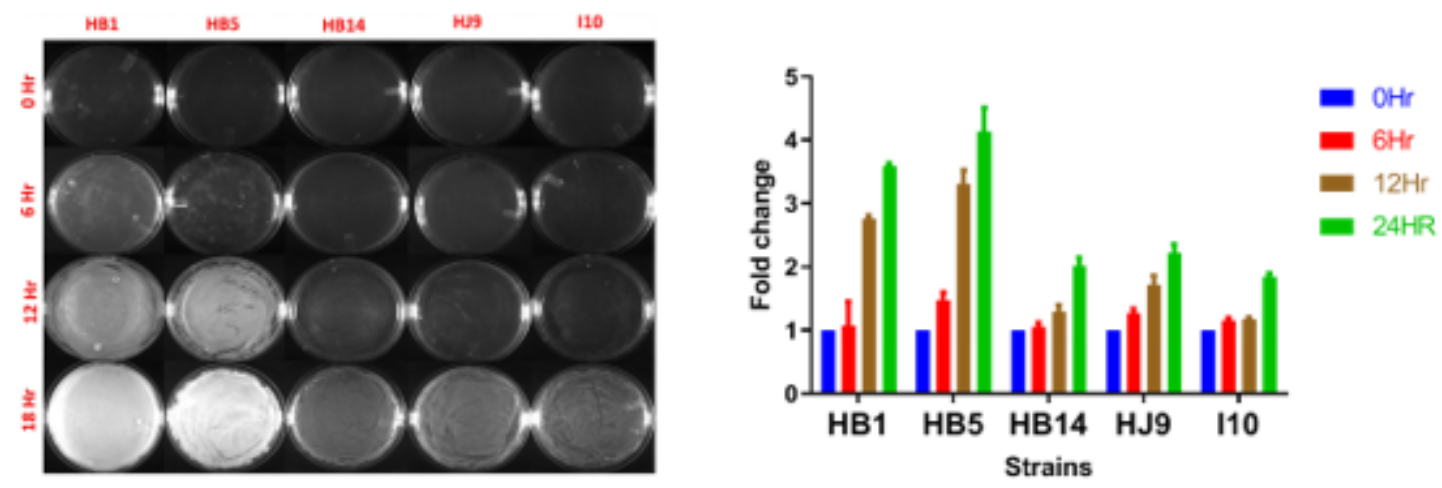

Figure 2

Growth pattern of isolated $\mathrm{H}$. pylori strains. (a) The growth pattern of clinical isolates (HJ1, HB1, HB4, HB5, HJ9, HJ10, HB10, HJ14, HB14) and reference strain (I10) under specific microaerophilic condition assessed at 0,6, 12, 18 and 24hrs. The data are the mean $\pm S D(n=4)$ of two independent experiments with technical replicate. (b): Graphs are plotted for relative growth in comparison to I10 at 0, 2, 6, 12, 18 and 24hrs. (c) Plate densitometry image of selected H. pylori isolates HB1 (lane 1st); HB5 (lane 2nd ); 
HB14 (lane 3rd); HJ9 (lane 4th); and I10 (lane 5th ) are showing growth till 24hrs. The experiment is performed in duplicates and the representative images are shown. (d) Fold change calculated in comparison to $0 \mathrm{Hr}$
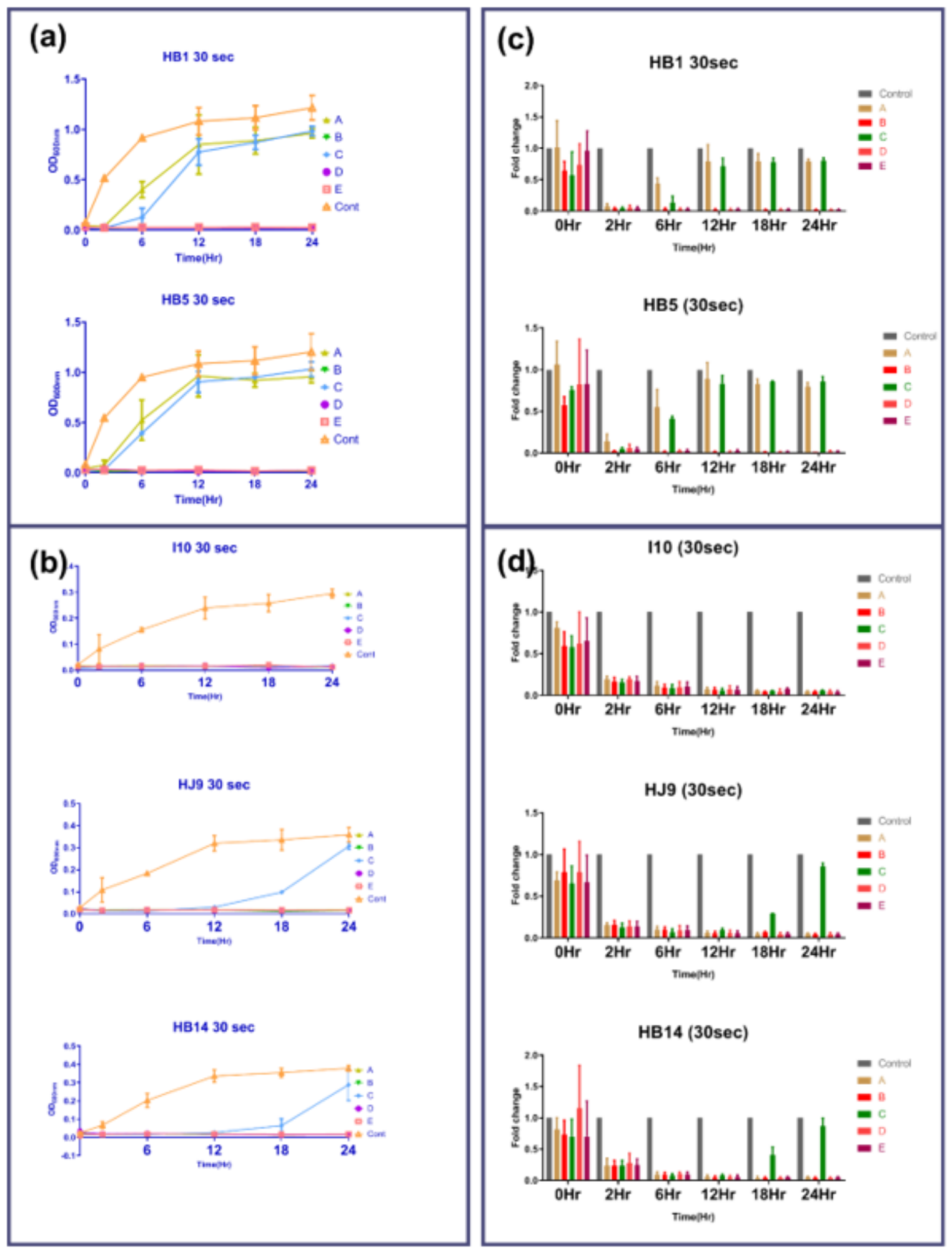

Figure 3

Growth pattern of $\mathrm{H}$. pylori isolates after chemical treatment for $30 \mathrm{sec}$. Treatment of chemicals (A, B, C, D and E) was given to 6 X107 of H. pylori for 30sec and growth was observed until 24hrs compared to 
untreated control. Graphs reflect the growth of (a) fast (HB1 and HB5) and (b) slow growing (HJ9, HB14 and I10) isolates. Relative growth of (c) HB1, (d) HB5 (e) I10 was estimated compared to untreated control. The data are the mean $\pm S D$ of two independent experiments with technical replicate $(n=4$, mean \pm $\mathrm{SD})$.
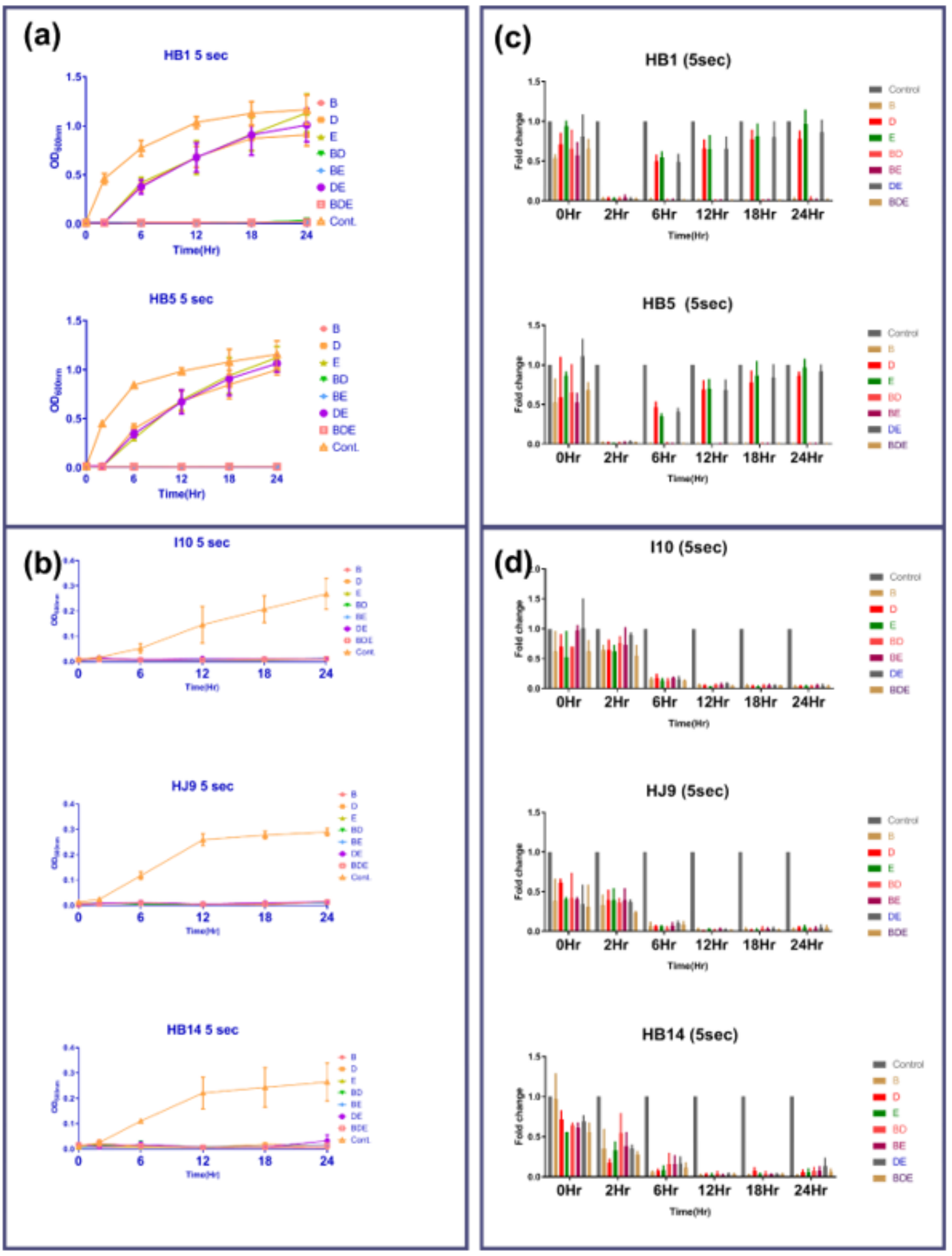

Figure 4 
Treatment with selected chemicals for a shorter duration. 6 X107 of $\mathrm{H}$. pylori were treated with selected chemicals alone and in combination (B, D, E, BD, BE, DE and BDE) for $5 \mathrm{sec}$. Growth was observed until 24 hrs in comparison to untreated control. Growth curve of (a) fast growing isolates (HB1 and HB5) and (b) slow growing isolates (HJ9, HB14 and I10). Relative growth of HB1, HB5, I10, HJ9 and HB14compared to untreated control. The data are the mean $\pm S D$ of two independent experiments with technical replicate $(n=4$, mean $\pm S D)$.
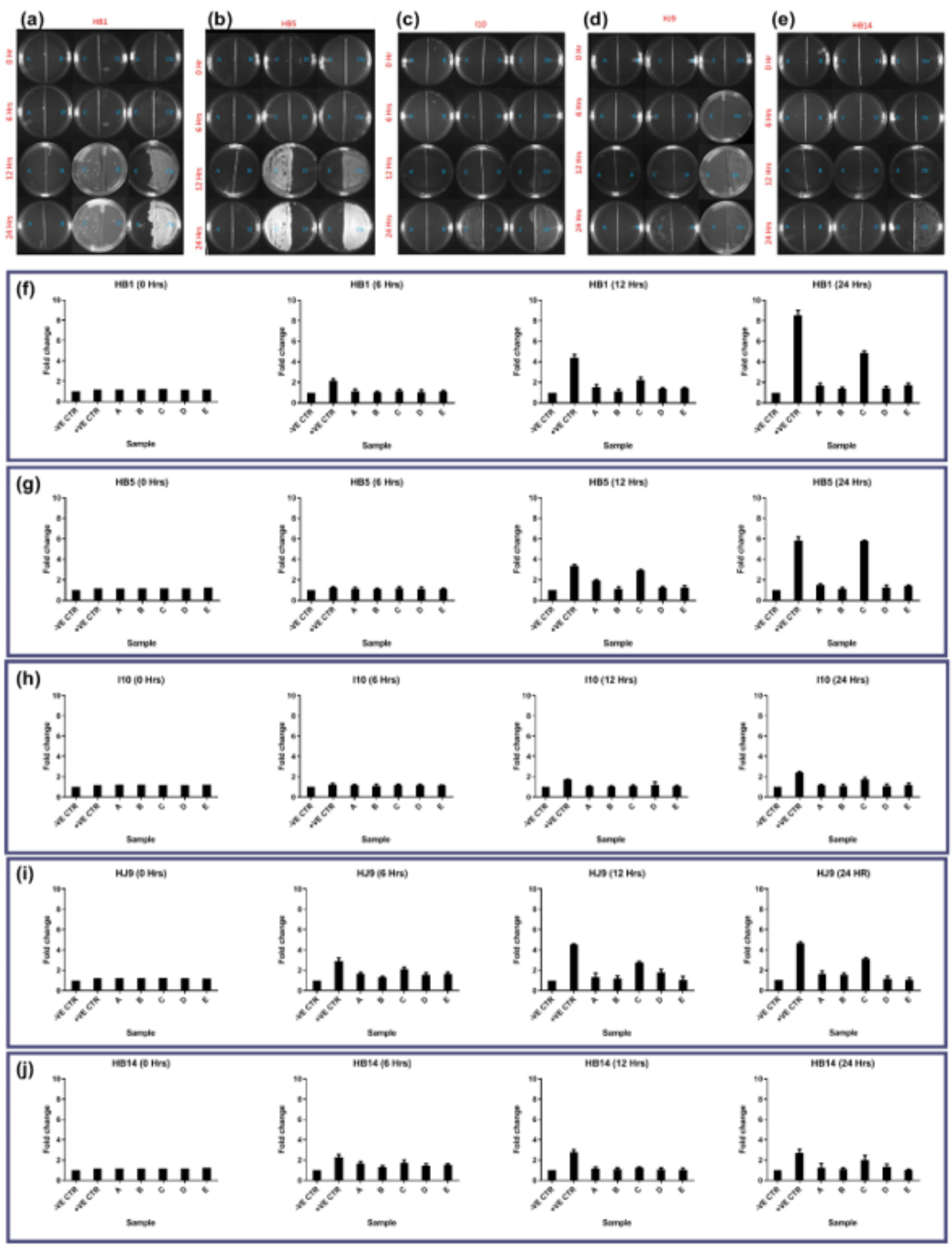

Figure 5 
Plate densitometry of $\mathrm{H}$. pylori after chemical treatment. Chemical treatment of $\mathrm{A}, \mathrm{B}, \mathrm{C}, \mathrm{D}$ and $\mathrm{E}$ was given to $1 \mathrm{X} 107 \mathrm{H}$. pylori followed by spreading on half of the BHI Agar plate. Representative images showing growth of (a) HB1, (b) HB5, (c) I10 (d) HJ9 and (e) HB14 till 24hrs. Relative growth was estimated for fast growing isolates (f) HB1 and (g) HB5; and slow growing isolates (h) I10, (i) HJ9 and (j) HB14. Blank plates were considered as negative control and untreated isolates as a positive control. The data are the mean $\pm S D$ of two independent experiments with technical replicate $(n=4$, mean $\pm S D)$

(a)

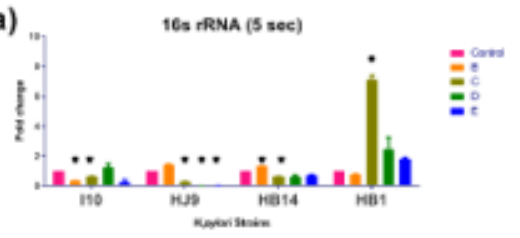

(c)

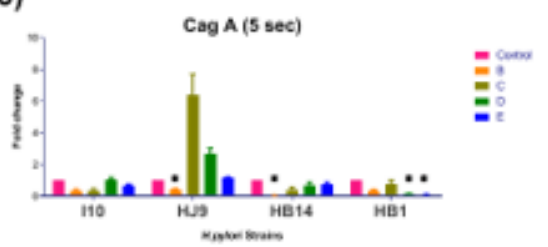

(e)

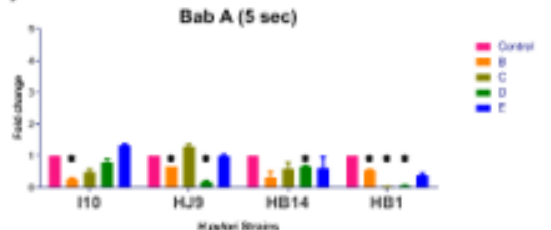

(g)

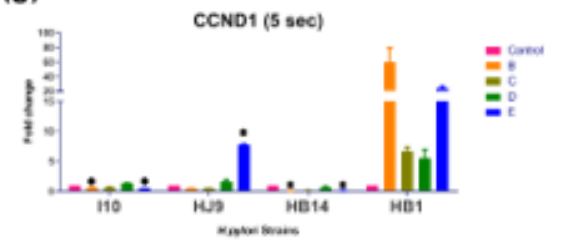

(i)

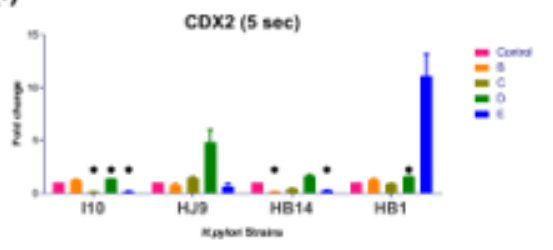

(k)

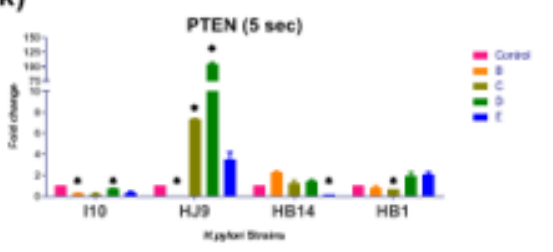

(m)

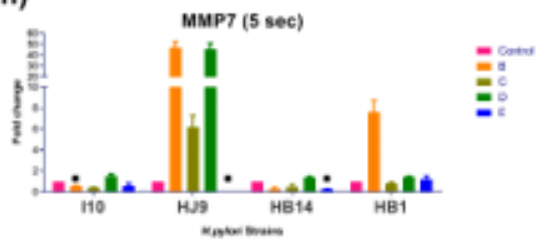

(b)

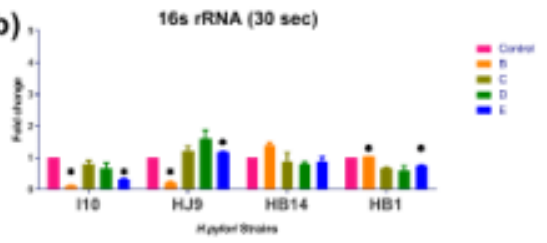

(1)

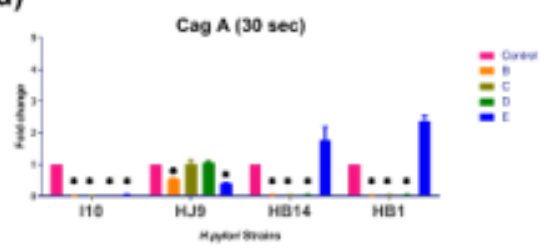

(f)

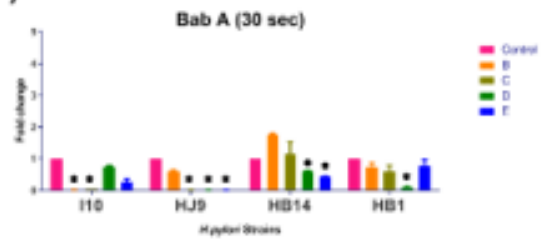

(h)

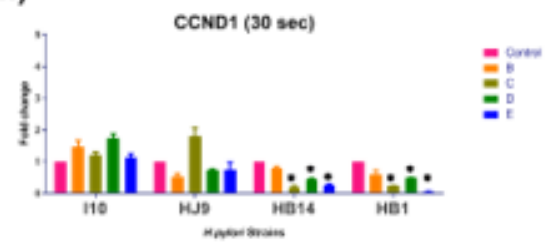

(j)

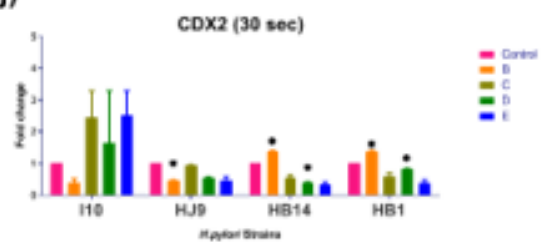

(I)

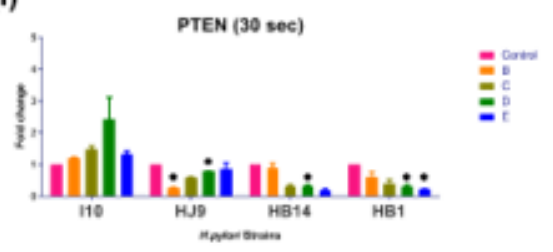

(n)

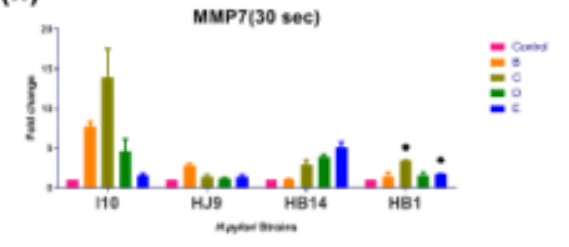

Figure 6 
Investigation of H. pylori and gastric cancer genes: Treatment of chemical was given to 6X107 of $\mathrm{H}$. pylori and incubated with $0.5 \times 106$ AGS cell for $12 \mathrm{Hrs}$. RNA was isolated and transcript level was determined by qRTPCR. Experiments were performed in duplicates. Expression of 16s rRNA (a,b); CagA $(\mathrm{c}, \mathrm{d})$; $\operatorname{BabA}(\mathrm{e}, \mathrm{f})$; CCND1 (g,h); CDX2 (i,j); PTEN (k,l); MMP7 $(\mathrm{m}, \mathrm{n})$ was evaluated on 5 and 30 sec treatment respectively.

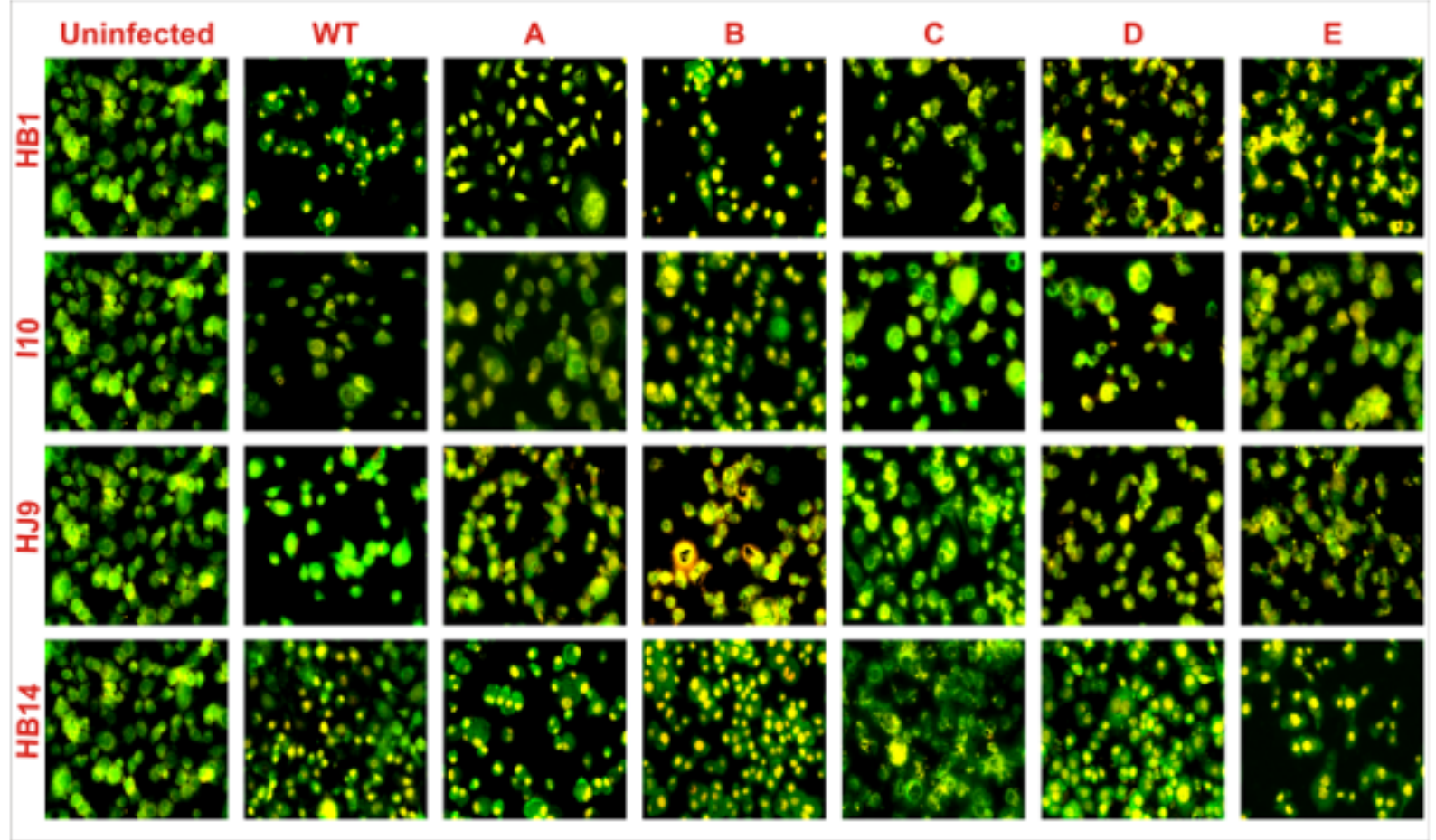

\section{Figure 7}

EB/AO dual staining assay. $0.25 \times 106$ AGS cells were plated in 6 well plates and infected with $30 \mathrm{sec}$ chemical (A, B, C, D and E) treated and wild type (WT) H. pylori isolates. Furthermore, 12 hrs post-infection the cells were stained with EB/AO solution and images were acquired. (a) HB1, (b) I10, (c) HJ9 and (d) HB14 infected and uninfected AGS cells 


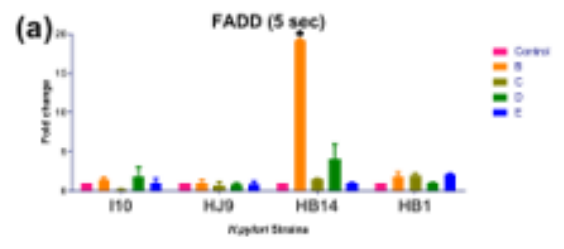

(c)

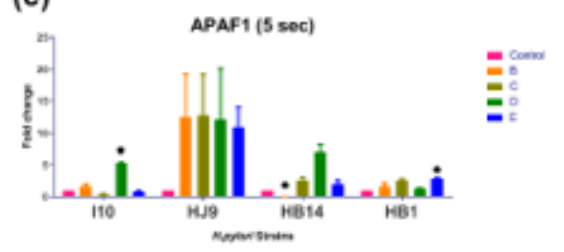

(e)

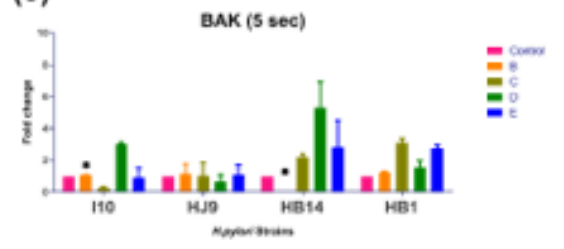

(g)

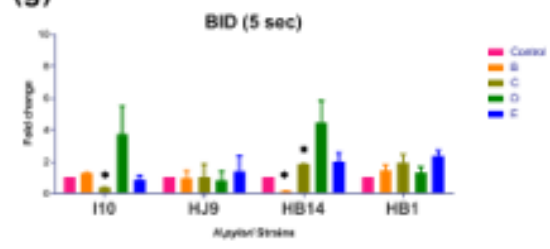

(i)

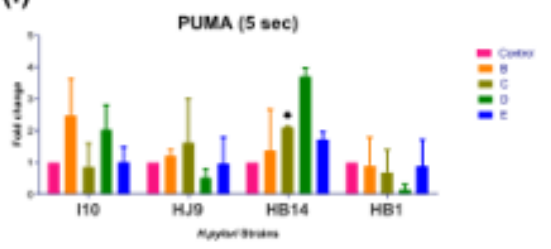

(k)

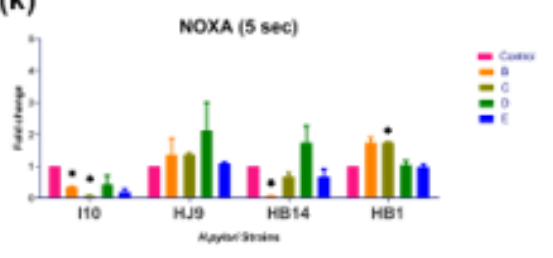

(m)

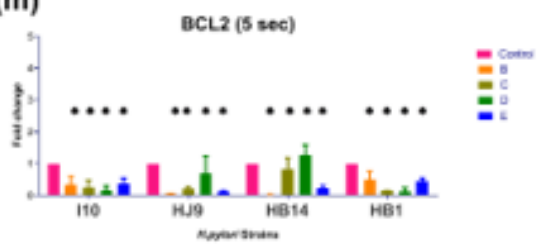

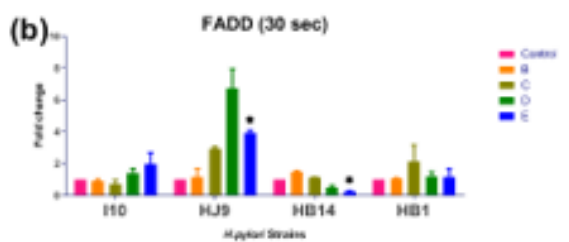

(d)

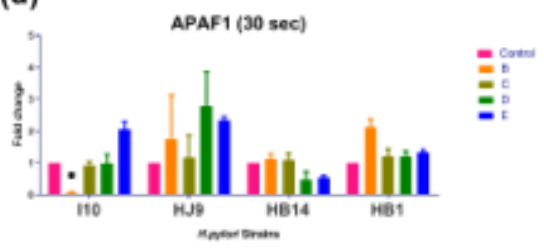

(f)

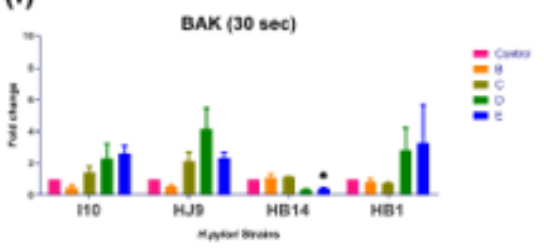

(h)
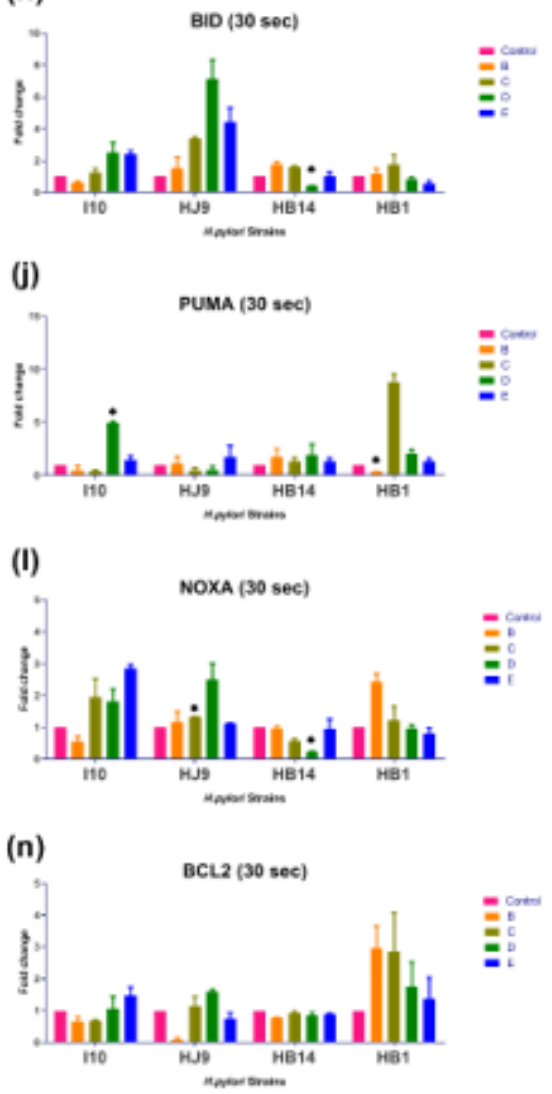

\section{Figure 8}

Status of apoptosis-related genes. Chemical treatment was given to $6 \times 107$ of $\mathrm{H}$. pylori and incubated with $0.5 \mathrm{X} 106 \mathrm{AGS}$ cell for $12 \mathrm{Hrs}$. RNA was isolated and the transcript level was determined by qRTPCR. Experiments were performed in duplicates. Expression of (a, b) FADD; $(c, d)$ APAF1; (e, f) BAK; $(g, h)$ BID; $(i$, j) PUMA; $(k, l)$ NOXA; and $(m, n) B c l 2$ was assessed after treatment for 5 and 30 sec respectively. The data are the mean \pm SEM of two independent experiments with technical replicate $(n=4)$ 


\section{Supplementary Files}

This is a list of supplementary files associated with this preprint. Click to download.

- SupplementaryFiguresBMCMicrobiology.pdf 